\title{
Permittivity and Permeability Characterization of SiC and Ferro Metals for Structural Health Monitoring Utilization
}

\author{
Alaa Raad Hussein ${ }^{1, *}$, Thar M. Badri Albarody ${ }^{1, \dagger}$, Puteri Sri Melor Bt M. Yousf ${ }^{1}$, Monis \\ Abdulmanan Abdullah ${ }^{1}$ and Husam Kareem Mohsin Al-Jothery ${ }^{1}$ \\ ${ }^{1}$ Mechanical Engineering Department, Universiti Teknologi PETRONAS, Malaysia
}

\begin{abstract}
The need for wireless sensing technology has rapidly increased recently, specifically the usage of electromagnetic waves which becoming more required as a source of information. Silicon carbide (SiC) Nano particles has been used in this study, the material under test (MUT) was exposed directly to a microwave field to examine the electromagnetic behavior. The permittivity and permeability were investigated with different filler materials to approach best and optimal electromagnetic absorbing characteristics to assist engineers to monitor structure-based composite for defects evaluation that may occur during operation conditions or through manufacturing process. XRD, FESEM and both complex permittivity and permeability were measured for the pure materials that candidate for this study. The results showed that all the selected nanostructure material exhibit a good purity with proper electromagnetic properties in the X-band, this can lead to absorbing and transmission properties that can be used in monitoring structures or manufactured part during fabrication process.
\end{abstract}

\section{Introduction}

Electromagnetic (EM) waves have involved in many sectors of daily life and industry, due to its unique properties that can provide a variety of information for a particular object. Recently, in the materials field EM took a considerable place of providing information to the manufacturer about the status of the product that met the requirement of quality or it may needs more enhancement to reach the optimal performance [1]. This wave (EM) is also considered as one of the most important sources of information in the field of nondestructive testing, for its reliability and confident of result or measurement for the materials or product parts during the procedure of manufacturing. This concept can be utilized in online monitoring for each product even if the production line or factory produce thousands of parts per day, especially for composite structure.

So, measurement the transmission ability is the key of checking products deeply (inside the structure) of the composite to evaluate any defects such as density variation or internal

\footnotetext{
* Corresponding author: alaaeng84@gmail.com

$\dagger$ Corresponding author :dher.albarody@utp.edu.my
} 
cracks for the ceramic products made from silicon carbide $(\mathrm{SiC})$ for example mechanical seal, sliding bearing and etc....

The application of $\mathrm{SiC}$ is widely used in military, commercial and aerospace industry due to its unique dielectric and electric properties, high stability at elevated temperature and good mechanical properties such as high strength, corrosion resistance low density and oxidation resistance [2-4]. Due to its semiconductor properties, it can be used in microelectronic devices and also, in nuclear industry as one of the most important structural ceramic $[2,5]$.

Structural or product part made from ceramic especially pure silicon carbide or composites of $\mathrm{SiC}$ supposed to have the ability to absorb the electromagnetic waves in low or high frequency, so, characterization of these materials in terms of purity and absorbability can be made directly in different ways in standard measurement technique, either reflection in free space from the tested product or structure of the EM wave or via measurement the transmitted waves from the final products [1]. The study of permittivity and permeability is quite important to understand the behavior of $\mathrm{SiC}$ composite when expose to high frequency, In addition, the absorbing material should allow the waves to penetrate as much as it can in case the object is thin or light, multi frequency and strong attenuation $[6,7]$. Particle size and dispersion concentration can influence the EM characteristics of materials to vary from low to high and good absorbing properties [8], as well as the dielectric loss and magnetic loss [9].

Many researches have been conducted to study the absorption properties of $\mathrm{SiC}$ in micro and nano size, but these studies did not saturate all the angels for $\mathrm{SiC}$ nano composites, because the studies in nano scale provide very large surface to volume ratio, this associated with high energy of composite when expose to high frequency demand [10]. This leads to a new behavior of composite when change the frequency band, these frequencies affect both permittivity $(\varepsilon)$ and permeability $(\mu)$ of the constituents of any composite, where $\varepsilon$ and $\mu$ represent the interaction of particles of material with electric and magnetic field respectively [11]. Nickel, zinc, graphene iron particles and zinc oxide used by [12-16] with variation of weight or volume ratio, these materials used separately either with $\mathrm{SiC}$ or with other ceramic powder but in most cases low number of researches done to investigate more than two constituent on the absorbing properties of $\mathrm{SiC}$ in high frequency. X. Yuan et al [17] used Xband to investigate the ( $\varepsilon$ and $\mu$ ) of monolithic ceramic composite of $\mathrm{SiC}_{\mathrm{SiO}}$, they studied the effect of microstructures on the EM absorbing performance, the results come out with contribution of microwave absorption prosperity when combine crystalline structure with amorphous material. On the other hand, [18] used SiC NWs as reinforcement fiber to enhance the mechanical properties of epoxy composite by investigated the hardness of the designed composite. Chiu et al [9] investigated absorbing properties of $\mathrm{SiC}$ in gigahertz range with different weight ratio, they proved that $\mathrm{SiC}$ exhibit good $\mathrm{EM}$ absorbability due to high surface area of the NWs. Wang et al [19] and Zhou et al [20] have studied the permittivity and permeability of two types of SiCf in X-Band beside the mechanical properties and morphology of the surface, the results show deviation between these two types of $\mathrm{SiC}$ due to the effect of fiber on the absorption properties of the SiCf/epoxy composite. Mixing particles with $\mathrm{SiC}$ that have good electric or magnetic properties has attracted the researchers in order to enhance the microwave absorbing of ceramic composite, $\mathrm{Ni}$ decorated $\mathrm{SiC}$ was investigated by Yuan et al [21] in different temperature ranges to report the effect of heat on the dielectric properties. The high temperature can adequately increase the absorption ability of the composite and the $\mathrm{Ni}$ as well. Moreover, nickel, cobalt and phosphorous with $\mathrm{SiC}$ composite also studied to understand the effect of cobalt on the dielectric and diamagnetic of $\mathrm{SiC}$ composite by $\mathrm{Yi} \mathrm{Li}$ et al [22]. This paper focuses on the characterization of two nano types of $\mathrm{SiC}$ (nano whisker and nano particles) with three nano fillers to enhance the absorbing ability of silicon carbide with different mixing ratios, these nano fillers $(\mathrm{ZnO}$, 
$\mathrm{Fe}_{2} \mathrm{O}_{3}$ and nickel) can be mix with any product of $\mathrm{SiC}$ with low mixing ratio, which leads to fast and confident monitoring of ceramic product over a broad frequency band.

\section{Experimental procedure}

The selecting starting materials used were $\beta$-SiC whisker and nanoparticles respectively ( $>99 \%$ purity, $10-200 \mu$ m length), $\mathrm{Fe}_{2} \mathrm{O}_{3}$ nanoparticles ( $>99.9 \%$ purity), $\mathrm{ZnO}$ ( $>99 \%$ purity) and amorphous $\mathrm{Ni}$ (99>\% purity) all powders were obtained from Hong Wu International Group Ltd. The average particle sizes for the nano powder are 100-300 nm, 100-200 nm, and 20-30 nm respectively. The mean grain size and morphology of the powders were verified by Field-Emission Scanning Electron Microscope (FE-SEM, Model Supra 55VP, Carl Zeiss AG). Crystalline characterization of $\mathrm{SiC}$ for both types and for the fillers were carried out by X-ray Powder Diffraction (XRD, Model X'Pert3 Powder, PANalytical, Cu, K- $\alpha$, $\lambda=1.540598$ ). XRD data was obtained over $2 \Theta$ range from $10^{\circ}$ to $80^{\circ}$ with the step size of $0.02^{\circ}$. Permittivity and permeability were measured using network analyzer type (ENA, Keysight E5071C) in the range of (8-12) GH using transmission line theory at room temperature. The epoxy used in this experiment was transparent to electromagnetic waves, dry mixing method was used to mix epoxy and $\mathrm{SiC}$ in desired weight ratio of $70 \mathrm{wt} \%$ of powder. The mixture is then pressed into rectangular shape with dimension of $(22.3 \mathrm{x} 10 \mathrm{x}$ 3) $\mathrm{mm}$ under $25 \mathrm{Mpa}$ for 3 minutes and cured in drying oven at $100^{\circ} \mathrm{C}$ for 1 hour.

\section{Result and discussion}

\subsection{Morphology and microstructure}

Characterization of beta Silicon Carbide Whisker $(\beta-\mathrm{SiC}), \mathrm{Fe}_{2} \mathrm{O}_{3}, \mathrm{Ni}$ and $\mathrm{ZnO}$ were carried out to verify the formation, morphology and purity of the powder. Fig. 1 (a) - (d) shows the FE-SEM image of the mentioned nano powder. It clearly shown in Fig.1(a) the whisker shape and length of each particle of $\beta$-SiC whisker with very less impurities. $\mathrm{Fe}_{2} \mathrm{O}_{3}$ nanoparticles which milled in ball milling for four hours were shown in Fig. 1(b), the shape of particles seems like nano rods with size of about 100-300 nm due to the milling process, these particles indicate high surface area which is beneficial for EM absorbing properties. On the other hand, Ni nano powder Fig. 1(c) shows unclear morphology of the particle surface, which is related to amorphous structures due to non-periodic or random distribution of atoms in the molecule. This behavior can be seen in XRD analysis in Fig. 2 as well. Nano rods $\mathrm{ZnO}$ morphology was shown in Fig. 1(d), uniform shape for each particle is clearly observed with almost one direction distribution.

XRD pattern of $\beta-\mathrm{SiC}, \mathrm{SiC}$ nano particles, $\mathrm{Ni}, \mathrm{Fe}_{2} \mathrm{O}_{3}$ and $\mathrm{ZnO}$ are presented in Fig. 2. Obvious XRD peaks are observed in Fig. 2(a) and (b), the detected peaks at position $2 \theta$ $(21.84,31.16,35.65,41.4,59.99$ and 71.78$)$ and $(35.64,41.39,59.97$ and 71.76) of which correspond to $(011,012,111,002,022$ and 113) and $(111,002,022$ and 113) related to both $\beta-\mathrm{SiC}$ and $\mathrm{SiC}$ nano particles respectively. The results clearly showed that the $\mathrm{SiC}$ used in this study is in crystalline phase, cubic structure. On the other hand, broad diffraction peaks are observed in nickel's particles with no visible crystalline peaks patterns as seen in Fig. 2(c), this match with the FE-SEM result of amorphous particles. Opposite to $\mathrm{Ni}$, the magnetite $\mathrm{Fe}_{2} \mathrm{O}_{3}$ exhibited one significant peaks indicate the intensity of iron particles marked with indices (202) correspond to diffraction angle 27.96, low peaks obtained in the sample which seems like kind of amorphous due to oxidation in particles after drying. The observation of $\mathrm{ZnO}$ appeared high purity of $\mathrm{Zn}$ with oxidation peaks, the indices of XRD 
peaks are $(010,002,011,012,110,013,112,021$ and 022$)$ which equal to $(31.61,34.33$, 36.09, 47.36, 56.30, 62.64, 67.63, 68.73 and 76.58) Fig. 2(e)

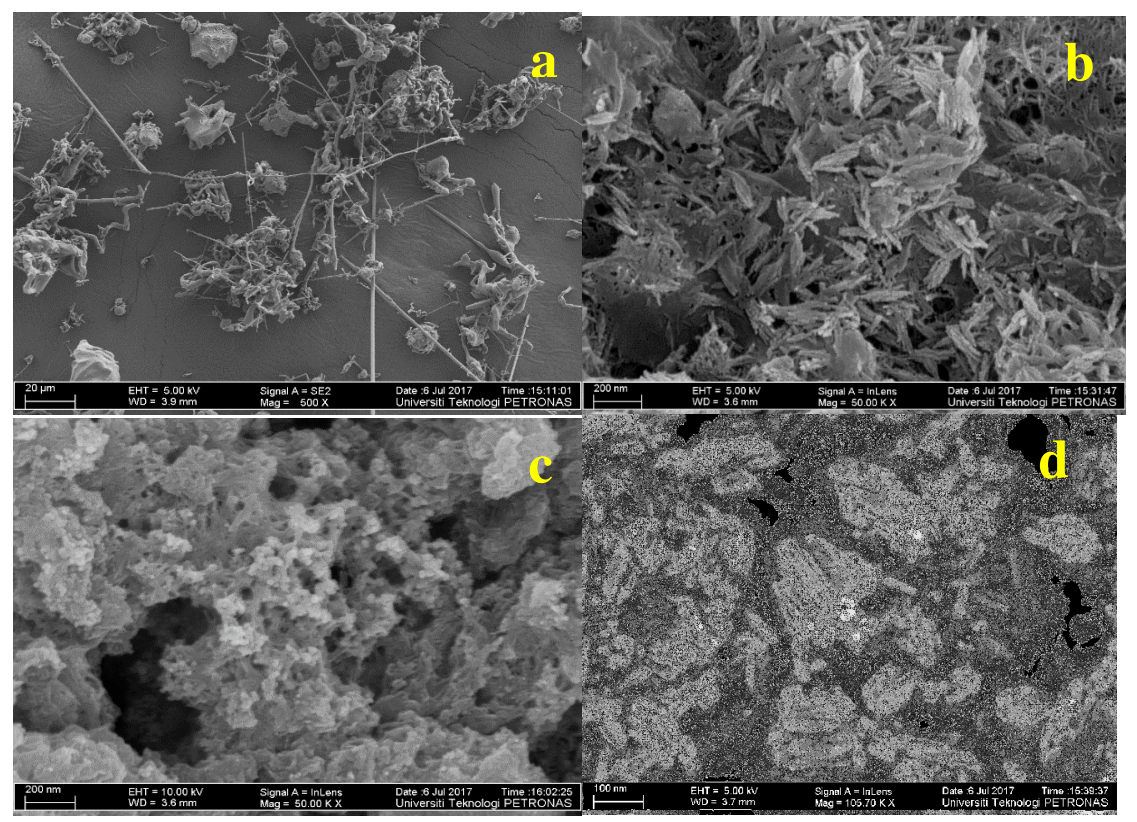

Fig. 1. FE-SEM for a) Silicon Carbide Whisker ( $\beta$-SiC), b) $\mathrm{Fe}_{2} \mathrm{O}_{3}$, c) $\mathrm{Ni}$, d) $\mathrm{ZnO}$
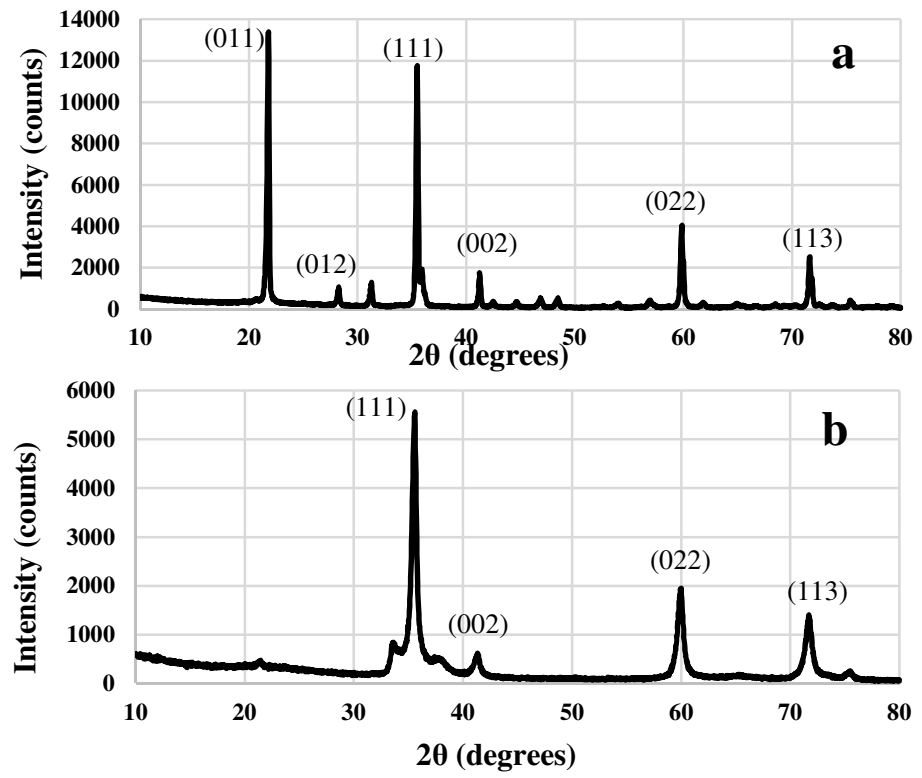

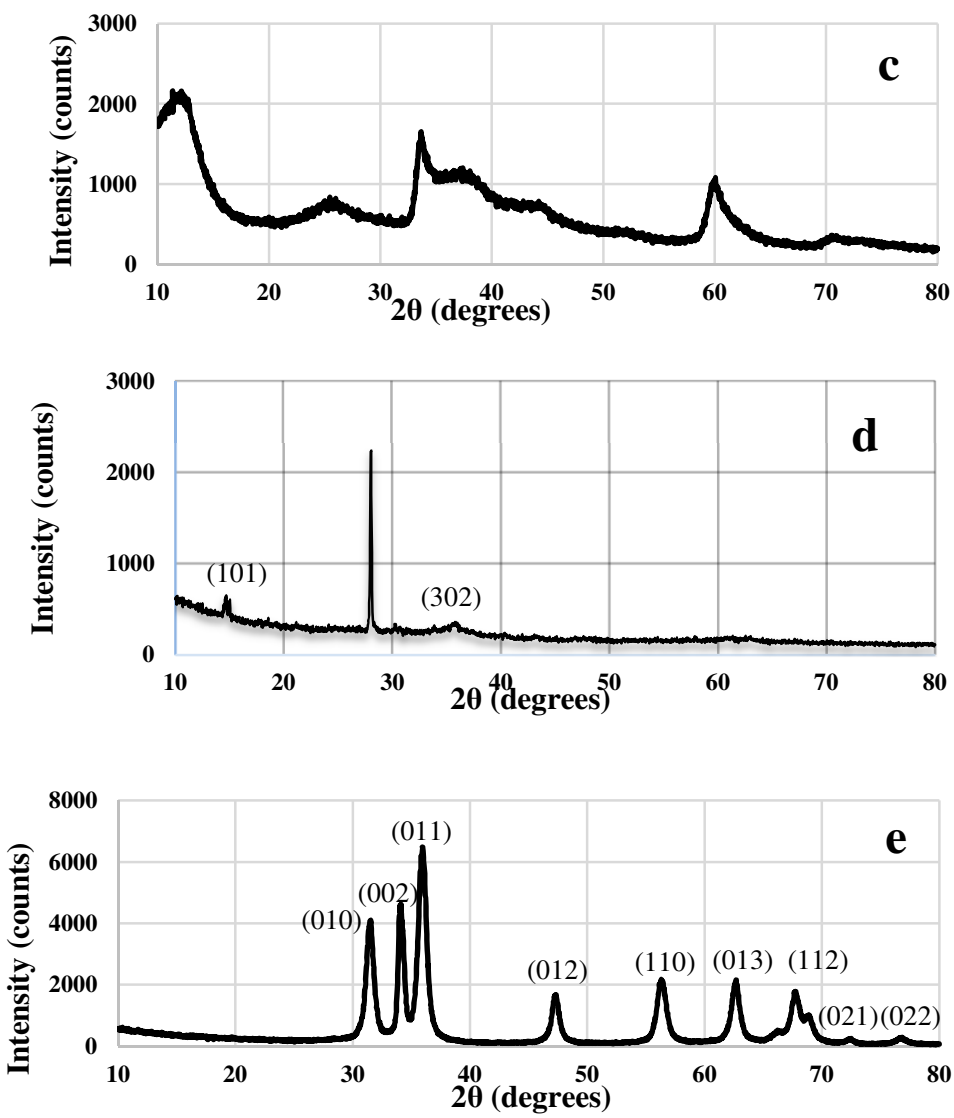

Fig. 2. XRD- pattern for a) Silicon Carbide Whisker ( $\beta$-SiC), b) SiC nano particles, c) Ni, d) $\mathrm{Fe}_{2} \mathrm{O}_{3}$, e) $\mathrm{ZnO}$

\section{Absorption properties of EM wave}

The complex permittivity $\left(\varepsilon=\varepsilon^{\prime}-i \varepsilon^{\prime \prime}\right)$ and permeability $\left(\mu=\mu^{\prime}-i \mu^{\prime \prime}\right)$ of Nano powders are shown in Fig. 4 in the X-band range to investigate the dielectric properties of the materials especially $\mathrm{SiC}$ at room temperature. As observed, $\mathrm{SiC}$ whisker showed the highest value of permittivity due to high surface area with high porosity compared to other materials, as well as the rough surface of whisker and the network that may generated by whisker. As known that the real and imaginary part of complex permittivity represent the capability of material to store and dissipate energy respectively, also $\varepsilon$ ' represent the polarization of material when expose to electric field. This consists of interfacial polarization; this concept is illustrated in Fig. 3 (a) and (b); where SiC whisker shows a gradual increase in imaginary part when frequency increases. Opposite to other material, $\mathrm{Ni}$ started to rise after $12 \mathrm{GHz}$ were other materials almost stable, this related to its magnetic nature. The small amount of $\varepsilon^{\prime \prime}$ comes from the high resistivity of the materials except SiC whisker show low resistivity, when the frequency increases due to microwave attenuation. On the other hand, the permeability was introduced in Fig. 3(c) and (d), in the real part of $\mu$ $\mathrm{ZnO}$ showed the highest value of permeability comparing to other material, one broad peak was contributed in the $\mathrm{ZnO}$ at frequency $9.7 \mathrm{GHz}$ until $9.9 \mathrm{GHz}$ which means a broad resonance lasted along this range of frequency. Nickel exhibit gradual decrease of magnetic 
absorption ability due its magnetic nature after $11 \mathrm{GHz}$ which reached the saturation point of magnetization. In the same manner all the other materials got almost same trend, but for $\mathrm{SiC}$ whisker the decrease in real permeability is due to diamagnetic characteristic. Some broad resonance peaks can be seen at range $9.5-10 \mathrm{GHz}$ with maximum value of 1.172 at 9.964 $\mathrm{GHz}, 1.144$ at $9.96 \mathrm{GHz}, 0.911$ at $9.88 \mathrm{GHz}$ for $\mathrm{Ni}, \mathrm{Fe}_{2} \mathrm{O}_{4}$ and $\mathrm{SiC}$ whisker respectively, in which natural resonance occurred in these materials [16]. This phenomenon (multi resonance) explained the effect of grain size on the magnetic behavior of nanoscale powder, also the large surface area compare to volume of nano powder allows for more absorbing ability, which also allow to carry more energy. The imaginary part exhibited also some resonance peaks for $\mathrm{Fe}_{2} \mathrm{O}_{3}, \mathrm{ZnO}$ and $\mathrm{SiC}$ whisker mean while nickels particles tend to increase because of the amorphous structure and eddy current effect. From Fig. 4d, it can be observed that most values of $\mathrm{SiC}$ nano particles and all values of $\mathrm{SiC}$ whisker are in negative, this can be explained by some noise during testing and the most crucial factor to be noticed is indicating through the left hand materials (LHS) as mentioned in some studies or it may include initially LHM properties which clearly shown in SiC whisker. In comparison between $\left(\varepsilon^{\prime}, \varepsilon ', \mu\right.$ ' and $\mu$ '”), the values of permittivity are much larger than the values of permeability due to the significant dielectric loss.
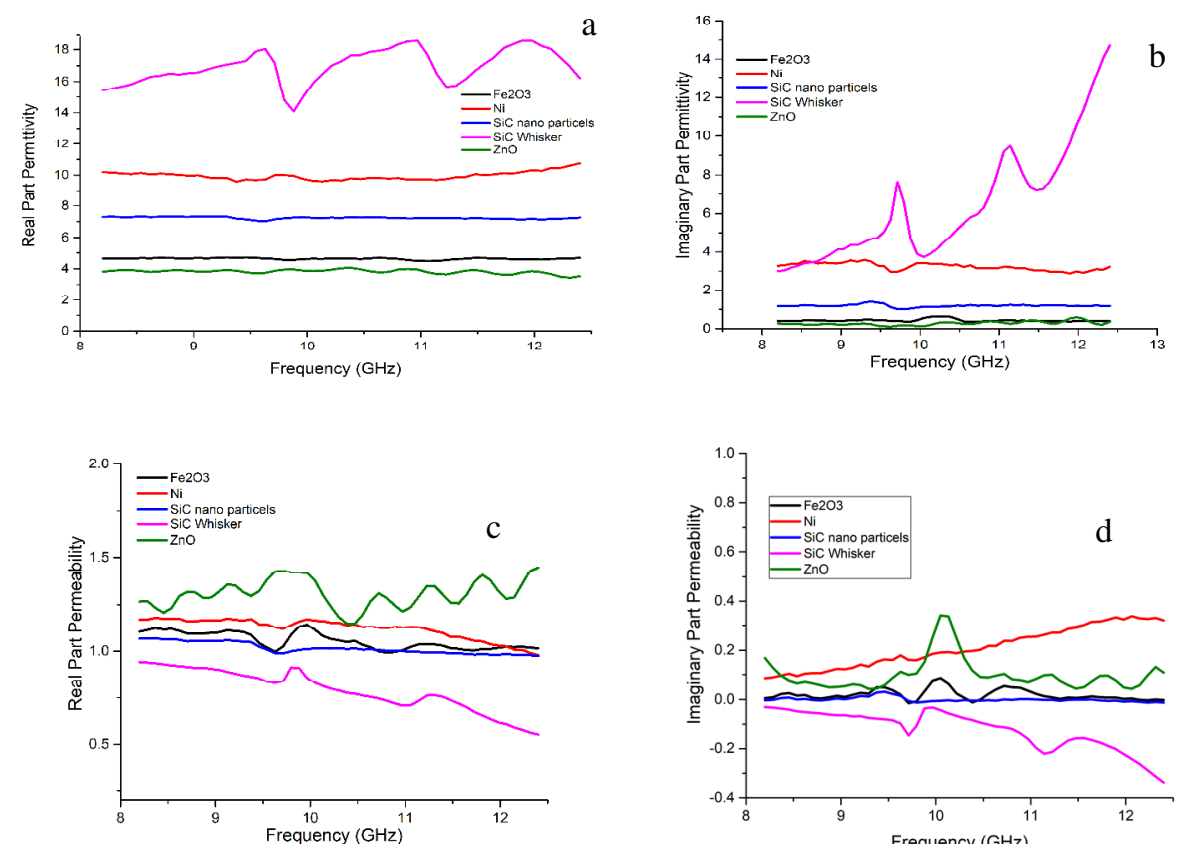

Fig. 3. EM properties a) RP permittivity, b) IP permittivity, c) RP permeability, d) IP permeability

\section{Conclusion}

The characterizations of the selected materials were investigated in terms of (FESEM, XRD, XPS and microwave absorbing capability). The results demonstrated that the particles are in nano scale with high purity, as well as the microstructure investigation showed that $\mathrm{Ni}$ is an amorphous structure with broad XRD peaks. On the other hand, the EM absorbing behavior of the nano powder indicated ability to EM absorbing characteristic of SiC nano particles and other fillers with high reflection for whisker which is mainly related to its 
dielectric properties, this can be figured out that $\mathrm{SiC}$ whisker is a good electromagnetic reflector due to its high permittivity that exceed 10. So transmission of EM can be further promising in all materials except $\mathrm{SiC}$ whisker.

The author would like to thank department of mechanical engineering- Universiti Teknologi PETRONAS, Perak-Malaysia, for their kind technical and financial support under grant number (URIF 0153AA-B91) and the research and development center for the electromagnetic support at Universiti Teknologi PETRONAS.

\section{References}

1. B. Mušič, P. Venturini Strokovno, Informacije MIDEM. 41, (2011)

2. H. Yang Jing, L. Yuan, Y. Li, Z. Ling Hou, H Bo Jin, X. Yong Fang, M. Sheng Cao, Solid State Commun. 163, 1-6 (2013)

3. H. Liu, H. Cheng, J. Wang, G. Tang, J. Alloys Compd. 491, 248-251 (2010)

4. G. Bowen, D. Ding, L. Wang, J. Wu, R. Xiong, Mater. Res. Express 4, 056103 (2017)

5. B. Román-Manso, E. Domingues, F. M. Fifueiredo, M. Belmonte, P. Miranzo, J. Eur. Ceram. Soc. 35, 2723-2731 (2015)

6. Mashuri, M. A. Baqiya, Triwikantoro, E. Yahya, Darminto, the $4^{\text {th }}$ nanoscience and nanotechnology symposium 1415, 238-241 (2011)

7. S. Singh, S. Shukla, A. Kumar, D. Singh, J. Alloys Compd. 738, 448-460 (2018)

8. M. Naeimirad, A. Zadhoush, R.E. Neisiany, J. Compos. Mater. 50, 435-446 (2015)

9. S. Chiu Cheng, H C. Yu, Y. Y. Li, J. Phys. Chem. C 114, 1947-1952 (2010)

10. C. Brosseau, P. Talbot, J. Appl. Phys. 97, 104325 (2005)

11. C. Tsipogiannis, Lund University (2012)

12. J. Wu, J Colloid Interface Sci, 506, 217-226 (2017)

13. Y. Lai, S. Wang, D. Qian, S. Zhong, Y. Wang, S. Han, W. Jiang, Ceram. Int. 43, 1290412914 (2017)

14. T. Kondo, T. Aoki, K. Asano, S. Yoshikado, International Symposium on Electromagnetic Compatibility (IEEE Cat. No.99EX147) 397-400 (1999)

15. S. S. Kim, S. T. Kim, Y. C. Yoon, K. S. Lee, J. Appl. Phys. 97, 10F905 (2005)

16. Z. H. Wang, L. W. Jiang, D. Li, J. J. Jiang, S. Ma, H. Wang, D. Y. Geng, J. An, J. He, W. Liu, Z. D. Zhang, J. Appl. Phys. 115, 17A527 (2014)

17. X. Yuan, L. Cheng, L. Zhang, J. Alloys Compd. 680, 604-611 (2016)

18. W. Nhuapeng, W. Thamjaree, S. Kumfu, P. Singjai, T. Tunkasiri, C. Appl. Phys. 8, 295299 (2008)

19. H. Wang, D. Zhu, X. Wang, F. Luo, Composites Part A 93, 10-17 (2017)

20. W. Zhou, L. Long, P. Xiao, Y. Li, H. Luo, W.-d. Hu, R.-M. Yin, Ceram. Int. 43, 56285634 (2017)

21. J. Yuan, H.- J. Yang, Z.-L. Hou, W.-L. Song, Y.-Q. Kang, H.-B. Jin, X.-Y. Fang, M.-S. Cao, Powder Technol. 237, 309-313 (2013)

22. Y. Li, R. Wang, F. Qi, C. Wang, Appl. Surf. Sci. 254, 4708-4715 (2008) 